\title{
Azathioprine Pharmacogenetics: The Relationship between 6-Thioguanine Nucleotides and Thiopurine Methyltransferase in Patients after Heart and Kidney Transplantation
}

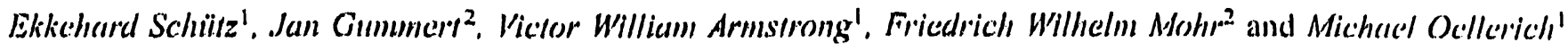

1 Abtcilung Klinische Chemic, Zentrum Innere Medizin

2 Abtcilung Thorax-, Her\%- und Geliißschirurgic, Zentrum Chirurgic

Georg-August-Universitït Gï̈ttingen, Götlingen, Germany

Dedicaleal to Prof. Dr. Dr: .J. Büttner on the occeasion of his' 65th birlluday"

Summary: The commonly used immunosuppressive regimen after solid organ transplantation consists of cyclosporine $A$, azathioprine and steroids. Azalhioprine, which is known to carry the risk of severe myelosuppression, is catabolized in vivo by xanthine oxidase and thiopurine methyltransferase, an enzyme which exhibits a common genctic polymorphism; $11 \%$ of Caucasians are hetcrozygous and $0.3 \%$ are homo\%ygous wilh respect to thiopurine methyltransferase deficiency. Toxicity and immunosuppressive effects have been attributed to the 6-thioguanine nucleotides gencrated from azathioprine. We have sludied thiopurine methyltransferase activity and g-llioguanine nucleotide concentritions in erythrocytes from 39 heart and kidney recipients. Erythrocyle thiopurine melhyltransferase was determined by a radiocnzymatic assay and crythrocyte 6-thioguanine nucleolide concentration with IIPLC. Thiopurine methyltransferase activity [median (range, $10^{\text {th }}-90^{\text {th }}$ percentile)] was significantly $(p<0.05$ ) higher in patients $(n=39)$ receiving ikathioprine $[285(218-362)$ vs. $262(160-352) \mathrm{mU} / \mathrm{l}$ erythrocyles] than in healthy blood donors as controls $(n=120)$. When stratified according to thiopurine methyllransferasc phenotype, onc patient homozygous for the low allele cxhibitcd an excessive crythrocyle 6-lhioguanine nucleotide concentration (2210 pmol/0.8 $10^{\prime \prime}$ erythrocytes). Helcrorygous patients had significantly higher 6-lhioguanine nucleotide concentrations (median: $435 \mathrm{pmol} /\left(0.8 \cdot 10^{\prime \prime}\right.$ crythrocyles) compared with concentrations in palients homozygous for the high allele (median: $86 \mathrm{pmol} / 0.8 \cdot 10^{\circ}$ erythrocyles; $p<0.01$ ), allhough the azillhioprine dosage did not difler $(p=0.66)$. Erythrocyte thiopurine methyltransferase determination thercfore identifies patients at high risk of acellmulating 6-thioguanine nucleotides. The monitoring of this enryme may contribute to the safer management of immunosuppressive therapy with arathioprine. Alternative regimens such as cyclosporin $\mathrm{A} /$ mycophenolate mofetil or tacrolimus should also be considured for this patient group.

\section{Introduction}

In immunosuppressive cyclosporin-based triple therapy after organ transplantation, azathioprine is often used as an antiproliferative agent. Azallioprine represents the Simidazole derivative of 6-merciplopurine and is rapidly clcaved to this drug in vivo by glutathione-S-transferisc (1). It is gencrally agreed that 6-thioguanine nucleotides, which are synthesised from 6-mercaptopurine through several enzymatic steps including hypoxanthine-guanine-phosphoribosyl transferase (2), are the major toxic species of 6-thiopurine derivatives (fig. 1) $(3,4)$. The determination of 6-thioguanine nucleotides in crythrocytes is therefore an acceptod means of estimating loxicity and efficacy of 6-mercaptopurine treatment in piltients with acute leukacmia (5-7) and after solid organ transplantation $(8-10)$. 6-Thiopurines are caltabolised by two enzymos, xanthine oxidase and thiopurine mellyyl-
Iransforase. Xinthine oxidase is not genctically polymorphic and if not pharmacologically blocked this patllway leads to 6-thiouric acid. In contrast, thiopurine melhyliransforase displays a common genetic polymorphism $(11-13)$. This polymorphism laads in $0.3 \%$ of Caucasians 10 a complete deficiency of the cnzyme, and in about 11\% to a heterozygous form will an enzyme activity of $40-60 \%$, compared with individuals with the two high alleles (14). An accumulation of 6-thioguaninc nucleotides is therefore likely to oecur if one of these catabolising patliways is altered. Thiopurine methyltransfertse is generally determined in erytlirocyles, which are readily accessible, and there is a close correlition between activities measured in erythrocyles and in other cells and organs e.g. liver, kidncy and leukocyles (15-17). Erythrocyte thiopurine methyllansterase of 


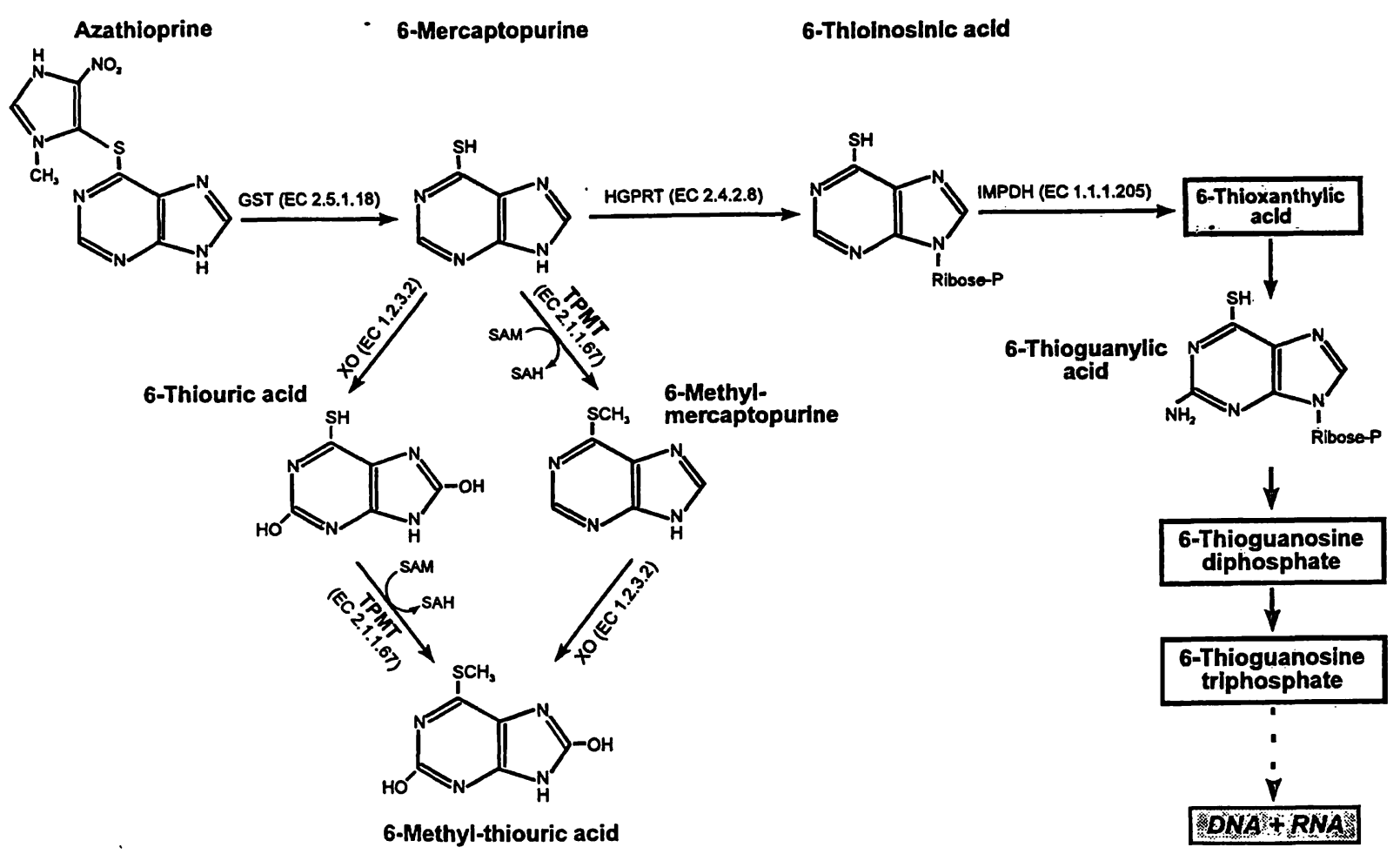

Fig. 1 Metabolic pathway of azathioprine

GST: Glutathione-S-transferase; HGPRT: hypoxanthine-guanine phosphoribosyl transferase; IMPDH:Inosine monophosphate dehy-

randomly selected healthy Europeans typically shows a biphasic frequency distribution, consistent with a codominant inheritance $(12,13)$. One single point mutation, which leads to a substantial reduction of catalytic activity has been described (18) and recently a predominant 2-point mutation, which is present in about $70 \%$ of thiopurine methyltransferase deficient subjects was discovered (19). Further factors complicating therapeutic management of thiopurines are their widely variable bioavailability $(20,21)$ and an increase of thiopurine methyltransferase activity during therapy consistent with an induction phenomenon $(10,22)$. These might be the main reasons for the fact, that until now, only one study has shown a close negative correlation between thiopurine methyltransferase and 6-thioguanine nucleotides (23).

In patients receiving thiopurines for malignancies, i. e. where leukocyte suppression is desired, the dosage is mainly adjusted to achieve low white blood cell count. In contrast, in immunosuppressive triple therapy, azathioprine is most commonly used in a protocol-based standard dosage and only reduced if leukopenia occurs. On the other hand, transplant recipients, compared with acute lymphatic leukaemia and acute myeloic leukaemia patients under maintenance therapy, are at higher risk for complications of leukopenia since they receive a combination of immunosuppressive drugs. They may therefore particularly profit from therapeutic drug monitoring of the toxic 6-thioguanine nucleotides. Furthermore, in these patients it would be of benefit to investigate the correlation of 6-thioguanine nucleotides and drogenase; XO: Xanthine oxidase; TPMT: Thiopurine methyl transferase; SAH: S-Adenosyl homocysteine; SAM: S-Adenosyl methionine

thiopurine methyltransferase in vivo, since if thiopurine methyltransferase phenotype is correlated with toxic metabolites, a stratification of each patient according to thiopurine methyltransferase activity prior to therapy may aid in planning subsequent immunosuppressive therapy, particularly with respect to the new immunosuppressants.

We studied erythrocyte thiopurine methyltransferase activity and 6-thioguanine nucleotide concentrations in 39 patients after heart and kidney transplantation under stable clinical conditions at least 3 months after the last blood transfusion, to elucidate the relationship between erythrocyte 6-thioguanine nucleotides and thiopurine methyltransferase activity.

\section{Patients and Methods}

\section{Probands}

Twenty-one heart transplant recipients and 18 kidney recipients with generally uncomplicated postoperative courses were included in this study. Thirty-eight patients had undergone transplantation at least 3 months prior to the investigation and none had blood transfusions within this time. The only exception was one thiopurine methyltransferase-deficient patient who was tested 2 months after transplantation. The immunosuppressive regimen consisted of cyclosporin $\mathrm{A}$, the dosage being adjusted according to its concentrations in blood $(200-350 \mu \mathrm{g} / \mathrm{l}$ in heart recipients, $150-200 \mu \mathrm{g} / \mathrm{l}$ in kidney recipients), steroids, which were tapered during the postoperative period, and azathioprine at a daily dosage median of $1 \mathrm{mg} / \mathrm{kg}$ body weight. Some patients received antilymphocyte antibodies as therapy induction for a maximum of 7 days immediately after transplantation. Patients with comedication with drugs which can potentially influence thiopurine metabolism, particularly xanthine oxidase inhibitors, and patients with unstable kidney function (e.g. due to rejection episodes) were excluded. If patients were 
tested several times, the latest time point was considered for statistical evaluation unless creatinine concentrations were increased compared with earlier measurements in the same patient.

For comparison, blood samples of 120 healthy blood donors were also analysed for their erythrocyte thiopurine methyltransferase activity.

\section{Methods}

\section{Erythrocyte preparation}

Erythrocytes were obtained from $\mathrm{NH}_{4}$-heparinate anticoagulated whole blood by centrifugation at $2000 \mathrm{~g}$ for $10 \mathrm{~min}$. Two washing steps were performed with Hank's balanced salt solution under the same conditions. Cells were finally rediluted to a haematocrit of about 0.40 and the exact haematocrit and red blood cell count for calculations of thiopurine methyltransferase activity and 6-thioguanine nucleotide concentration were determined with a Coulter STKS cell counting device. Samples were stored at $-90^{\circ} \mathrm{C}$ until analysis of thiopurine methyltransferase or 6-thioguanine nucleotides.

\section{Thiopurine methyltransferase assay}

Erythrocyte lysates were analysed for their thiopurine methyltransferase activity by a modified method according to Weinshilboum et al. (24). As proposed elsewhere, S-[methyl $\left.-{ }^{3} \mathrm{H}\right]$ adenosylmethionine was used as methyl donor (12) and the chelating step was omitted since erythrocytes lack interfering enzymes requiring bivalent cations (15). Lysates were incubated for $1 \mathrm{~h}$ at $37^{\circ} \mathrm{C}$ with 6-mercaptopurine, S-[methyl- $\left.{ }^{3} \mathrm{H}\right]$ adenosyl-methionine, dithiothreitol, and allopurinol. The formed [methyl $\left.{ }^{3} \mathrm{H}\right] 6$-mercaptopurine was liquid/liquid extracted with $120 \mathrm{mmol} / \mathrm{l}$ isoamyl alcohol in toluene and the radioactivity was determined by $\beta$-scintillation in a model LS3801 counter (Beckman Instruments, Munich, Germany). The radioactivity of the total reaction mixture was also determined. Results were corrected for quench, chemical and radiochemical purity of S-adenosylmethionine and extraction efficacy (56-65\%; determined in each run), and expressed as mU/l packed erythrocytes). These modifications yielded an improvement of between day variation of the erythrocyte thiopurine methyltransferase assay from $9.5 \%$ to $5.9 \%$. Within-series imprecision was $4.1-9.0 \%$ (100-350 $\mathrm{mU} / \mathrm{h}$ erythrocytes) in our laboratory with a dynamic range of this procedure of 17-920 $\mathrm{mU} / \mathrm{l}$ erythrocytes.

\section{6-Thioguanine nucleotide assay}

Erythrocyte lysates were hydrolysed in $1.5 \mathrm{~mol} / 1 \mathrm{H}_{2} \mathrm{SO}_{4}$ at $98^{\circ} \mathrm{C}$ for 1 hour, in order to convert the respective nucleotides to 6 thioguanine. A saturated solution of phenyl mercuric acetate in toluene/isoamyl alcohol at alkaline $\mathrm{pH}$ was used to extract compounds with sulfhydryl groups. After back-extraction into 100 $\mathrm{mmol} / \mathrm{HCl}$, samples were analysed by $\mathrm{C} 18$ reversed phase HPLC (Hypersil ODS $5 \mu \mathrm{m} 250 \cdot 4.6 \mathrm{~mm}, \mathrm{MZ}$ Analysentechnik, Mainz, Germany, guard column: RP select B $5 \mu \mathrm{m}$, Merck, Darmstadt, Germany) under isocratic conditions (25). 6-Thioguanine spiked drug-free erythrocyte lysates were used for construction of a calibration curve with UV detection at $342 \mathrm{~nm}$. 4-Mercapto-1H pyrazolo [3,4-d] pyrimidine was used as internal standard, and was detected at $322 \mathrm{~nm}$ (Shimadzu SPD 10 AV, Shimadzu Europe, GroBburgwedel, Germany). If deviation from the assigned haematocrit $(0.35)$ of sample preparation was $>0.05$, a correction was performed with donor blood or Hank's balanced salt solution prior to the hydrolysis step. This is necessary since extraction efficacy decreases with the number of erythrocytes, with a resulting optimum at an haematocrit of about 0.35 . Thioguanine concentrations were expressed as pmol $/ 0.8 \cdot 10^{9}$ erythrocytes. Between-days imprecision was $<7 \%$ at concentrations of $100 \mathrm{pmol} / 0.8 \cdot 10^{9}$ erythrocytes and above, with a detection limit of $20 \mathrm{pmol} / 0.8 \cdot 10^{9}$ erythrocytes.

All reagents were of highest available purity. S- $\left[\right.$ inethyl $\left.-{ }^{3} \mathrm{H}\right]$ adenosyl-methionine was purchased from Amersham (Braunschweig, Germany), isoamyl alcohol from J. T. Baker (Devender, The Netherlands) and toluene, borate, $\mathrm{H}_{2} \mathrm{SO}_{4}, \mathrm{HCl}$ and $\mathrm{NaOH}$ from Merck (Darmstadt, Germany). All other chemicals were from Sigma Chem. (Deisenhofen, Germany).

Statistical analyses were performed with SAS statistical package, Ver.6.01 (SAS Inst. New York, USA).

This study was approved by the local Ethics Committee.

\section{Results}

Erythrocyte thiopurine methyltransferase activity of 120 healthy donors showed a typical biphasic distribution (fig. 2) with a cut-off for the putative heterozygous group at $167 \mathrm{mU} / 1$ erythrocytes. The calculated cut-off

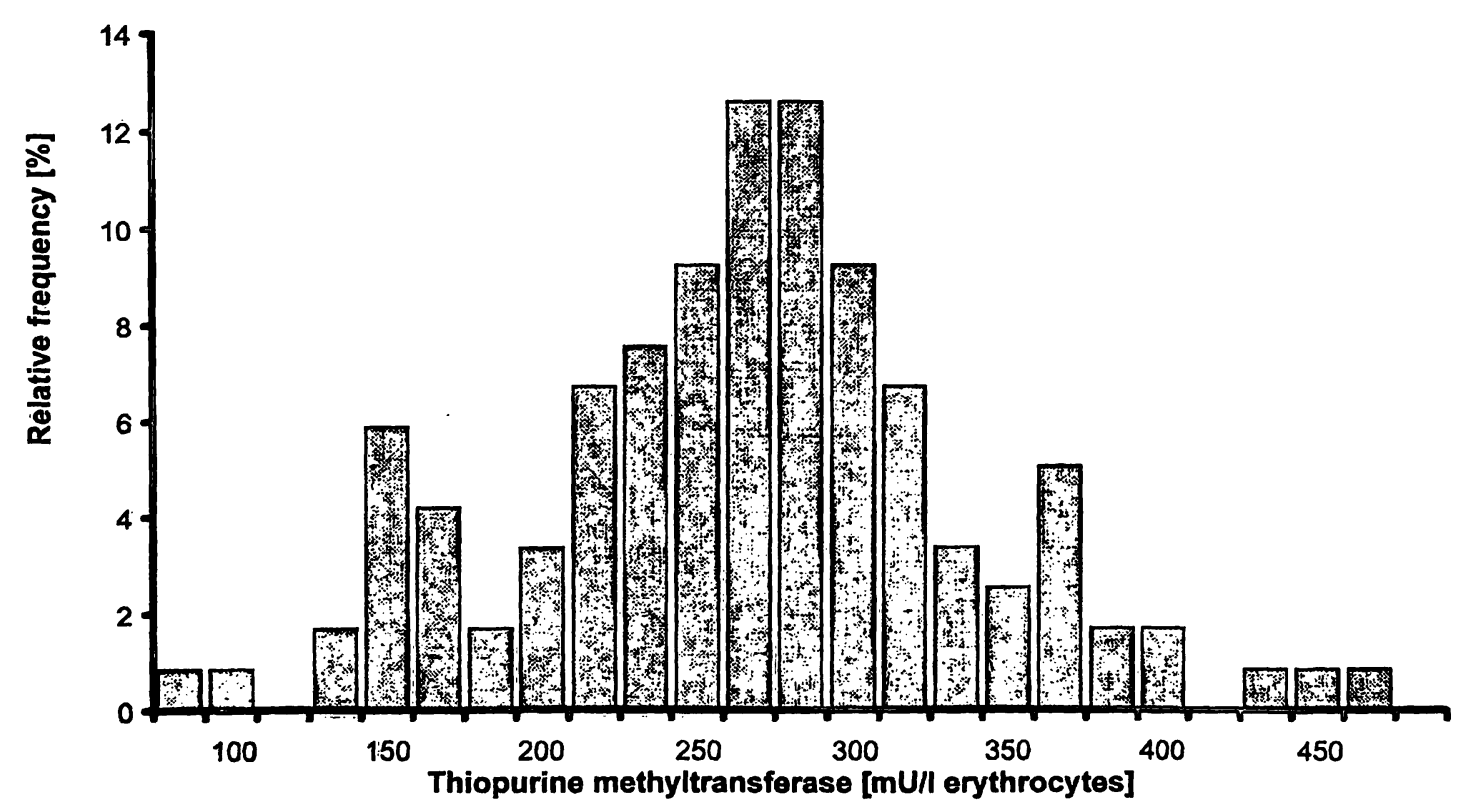

Fig. 2 Frequency distribution of erythrocyte thiopurine methyltransferase in 120 healthy blood donors without thiopurine administration. Groups are defined by their upper limit.
Typical biphasic distribution with calculated lower limit for the intermediate group of $162 \mathrm{mU} / \mathrm{h}$ erythrocytes 


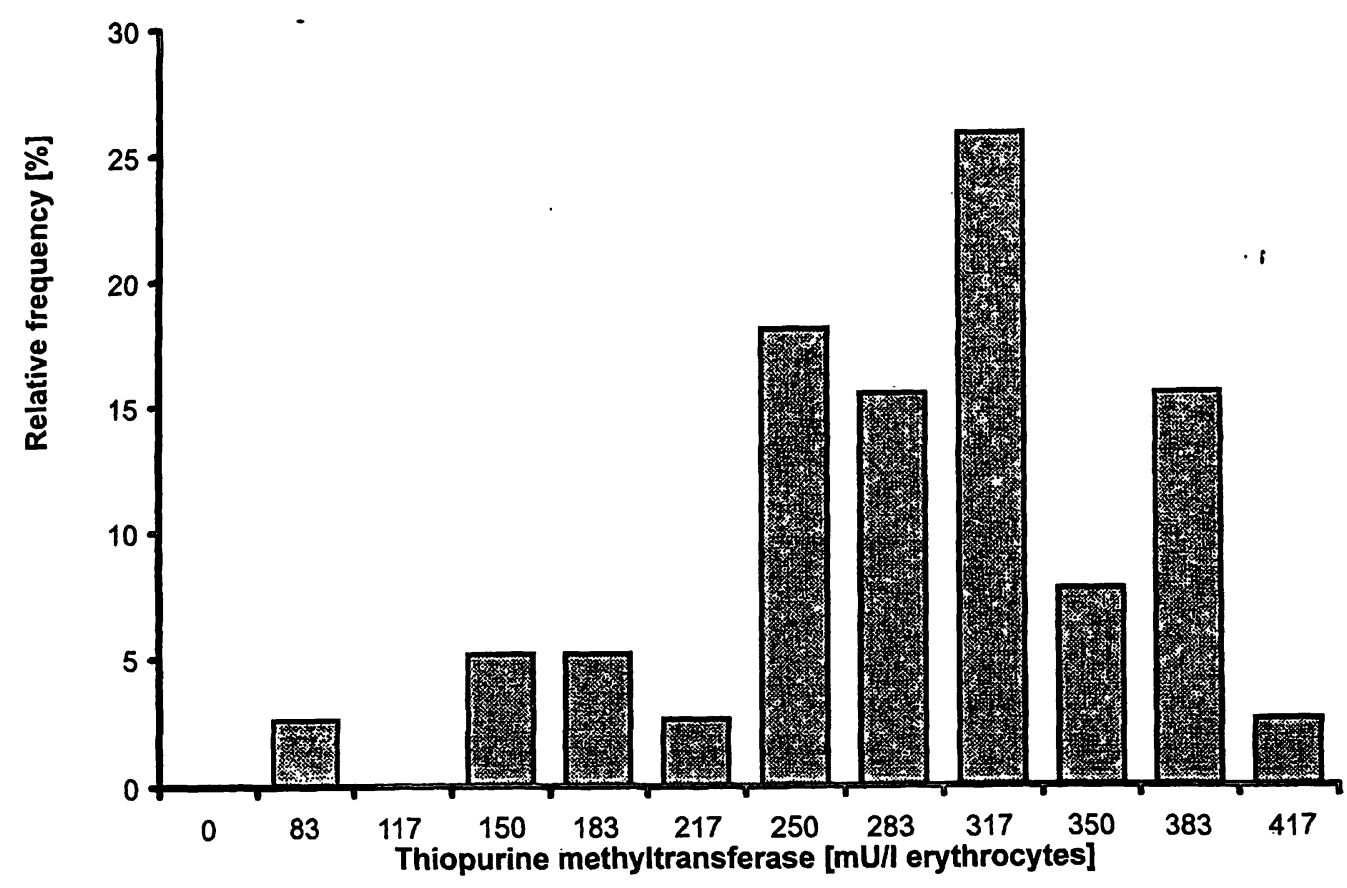

Fig. 3 Frequency distribution of erythrocyte thiopurine methyltransferase in 39 kidney and heart recipients under chronic azathioprine administration. Groups are defined by their upper limit.

point, based on the 11 th percentile of this donor group was $162 \mathrm{mU} / \mathrm{l}$ erythrocytes. The median for the whole group of healthy donors was significantly lower than in the group of patients under long-term therapy with azathioprine (262 vs. $285 \mathrm{mU} / \mathrm{l}$ erythrocytes; $\mathrm{p}<0.05$ ).

In the patient group, one subject showed a total thiopurine methyltransferase deficiency and five patients were identified with an intermediate phenotype (fig. 3). The upper limit of this intermediate group was $217 \mathrm{mU} / 1$ erythrocytes, defined as the 11 th percentile of the patient group with the exclusion of the thiopurine methyl- transferase deficient patient (since taking this case under consideration would over-represent this group, which has a frequency of $0.3 \%$ in a normal population).

Erythrocyte 6-thioguanine nucleotide concentrations displayed a broad distribution from 31 to $599 \mathrm{pmol} / 0.8$ $\cdot 10^{9}$ erythrocytes in patients with detectable erythrocyte thiopurine methyltransferase activity (fig. 4). The highest 6-thioguanine nucleotide concentration observed was $2210 \mathrm{pmol} / 0.8 \cdot 10^{9}$ erythrocytes in the thiopurine methyltransferase-deficient patient. This was associated with an episode of leukopenia.

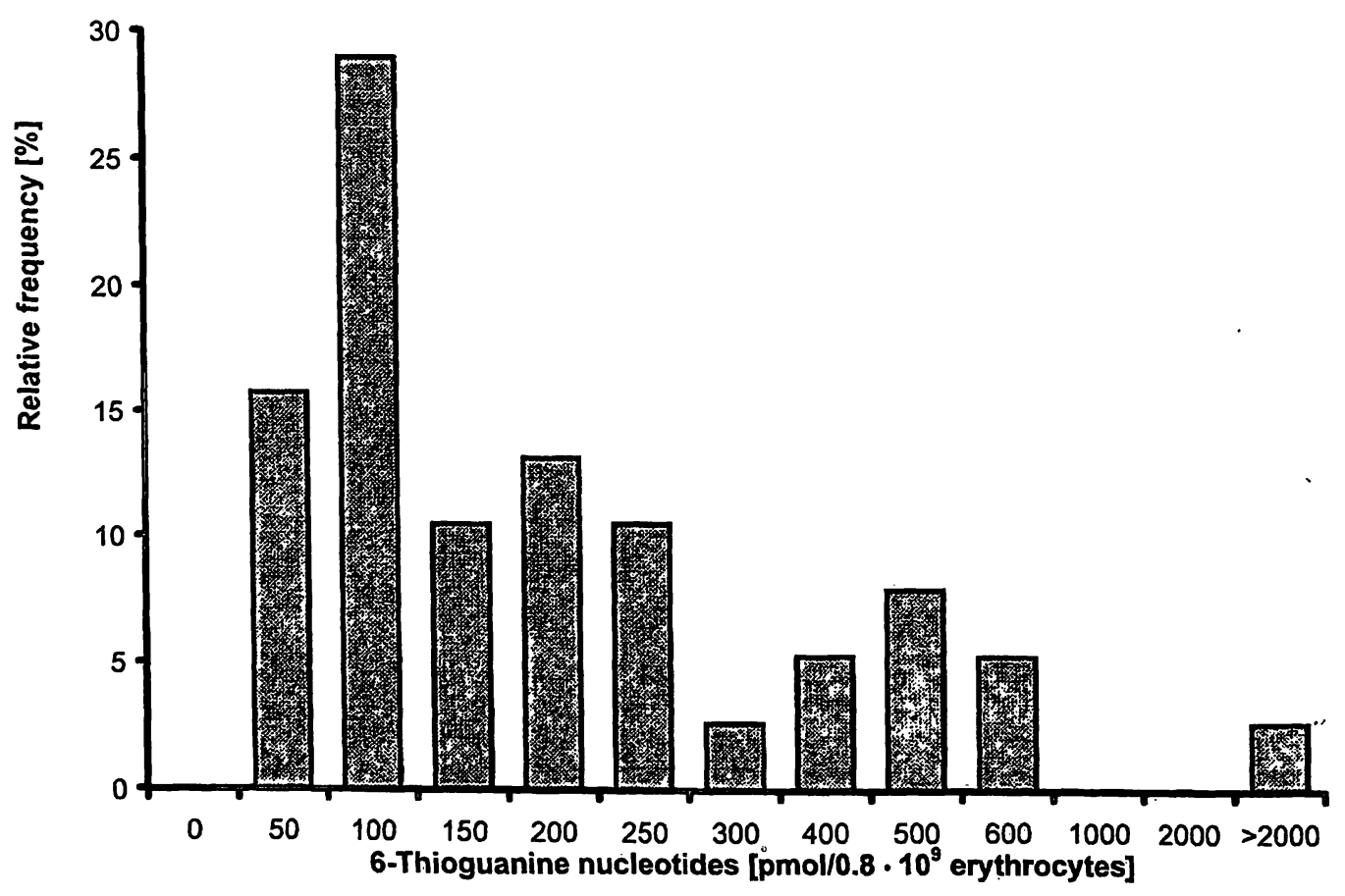

Fig. 4 Frequency distribution of erythrocyte 6-thioguanine nucleotides in 39 kidney and heartirecipients under chronic azathioprine administration. Groups are defined by their upper limit. 


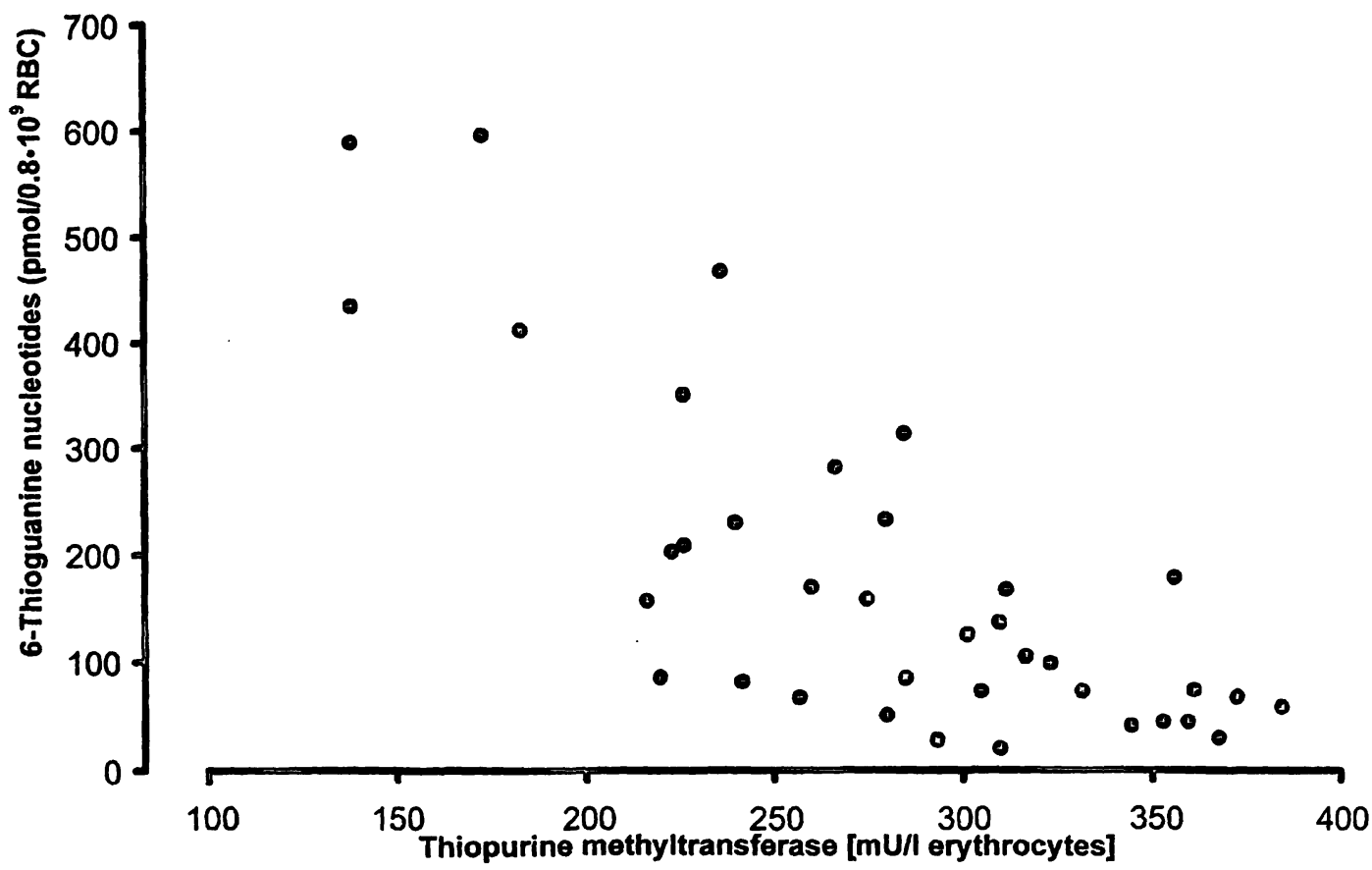

Fig. 5 Scatterplot of 6-thioguanine nucleotides vs. thiopurine methyltransferase in erythrocytes in patients receiving azathio- prine. One patient with thiopurine methyltransferase deficiency is not displayed $(n=38 ; r=-0.785)$.
Tab. 1 Erythrocyte 6-thioguanine nucleotide concentrations in heart and kidney recipients stratified according to erythrocyte thiopurine methyltransferase activity.

Thiopurine methyltransferase (mU/1 erythrocytes)

$\begin{array}{lll}<17 & 17-210 & >210 \\ (\mathrm{n}=1) & (\mathrm{n}=5) & (\mathrm{n}=33)\end{array}$

Thioguanine nucleotide concentration (pmol/0.8 $\cdot 10^{9}$ erythrocytes)

\begin{tabular}{lccr}
\hline Median & 2210 & $436^{*}$ & 99 \\
$84^{\text {th }}$ percentile & - & 593 & 228 \\
$16^{\text {th }}$ percentile & - & 321 & 46 \\
\hline
\end{tabular}

* $\mathrm{p}<0.05$ vs high thiopurine methyltransferase group

When stratified according to thiopurine methyltransferase activity, significantly higher erythrocyte 6-thioguanine nucleotide concentrations were observed in the groups with low thiopurine methyltransferase activity (tab. 1).

Azathioprine dosage did not differ between these groups (median $75 \mathrm{mg} /$ day; $\mathrm{p}=0.88$ ). Furthermore there was no correlation between azathioprine daily dose and erythrocyte-6-thioguanine nucleotide concentrations ( $r<0.01 ; p=0.431)$. A highly significant negative correlation was seen between thiopurine methyltransferase activity in erythrocytes and the respective concentrations of 6-thioguanine nucleotides (fig. 5), even when the patient with total thiopurine methyltransferase deficiency was excluded $(r=-0.785 ; p<0.01)$.

\section{Discussion}

The detoxification of azathioprine, used in immunosuppressive management after organ transplantation, is dependent on the common genetic polymorphism of thiopurine methyltransferase $(11-13,14,27)$. This study showed that thiopurine methyltransferase activity is obviously influenced by thiopurines and shows an increase under therapy. This is in close agreement with results from studies in which thiopurine methyltransferase was measured in patients prior to and under treatment with azathioprine or 6-mercaptopurine, and thereafter $(5,22)$.

Despite the well known metabolism of thiopurines, only one study has shown a close relationship between thiopurine methyltransferase activity and 6-thioguanine nucleotide concentrations (23). This might be due to several uncertainties of azathioprine therapy, such as the induction phenomenon mentioned above, different dosages, especially if dosage is adjusted according to leukocyte count, and the variable bioavailability of this drug $(20,21)$ which is influenced by food intake (26). In this study, we observed a close negative correlation of 6 thioguanine nucleotides and thiopurine methyltransferase in patients taking azathioprine. In these heart and kidney recipients, the observed highly significant correlation $(r=-0.785)$ was probably due to the relatively constant dosage of $75 \mathrm{mg} /$ day in this patient group.

High concentrations of erythrocyte 6-thioguanine nucleotides are associated with the risk of myelosuppression $(5-7,10)$, with related complications, such as septicaemia and consecutive multiple organ failure. As reported 
(27), the patient with complete thiopurine methyltransferase deficiency and excessive 6-thioguanine nucleotide concentration subsequently died from this complication. Furthermore in a previous study, we showed that patients with 6-thioguanine nucleotide concentrations $>600 \mathrm{pmol} / 0.8 \cdot 10^{9}$ erythrocytes may develop leukopenia (10). These findings suggest that one might expect an increased risk of toxic side effects in such patients under treatment with higher azathioprine dosage.

In therapeutic drug monitoring for azathioprine after solid organ transplantation the lower limit of erythrocyte 6-thioguanine nucleotides is hard to define, since the immunosuppressive regimen consists of a combination of drugs and there is a lack of simple quantities for assessing the immunosuppressive state of an individual patient. The data of this study demonstrate a close relationship between thiopurine methyltransferase activity and 6-thioguanine nucleotide concentration in transplant recipients under azathioprine therapy. It would therefore seem advisable to measure erythrocyte thiopurine methyltransferase prior to transplantation, to identify those patients with low or absent activity, who obviously carry an increased risk for toxic complications due to elevated 6-thioguanine nucleotides. In patients with lower or absent thiopurine methyltransferase, the concentrations of 6-thioguanine nucleotides should be monitored during azathioprine therapy to avoid toxic effects, and dosage could be adjusted at the start of therapy by taking erythrocyte thiopurine methyltransferase activity into account. Alternatively, determination of erythrocyte thiopurine methyltransferase prior to transplantation could be used to identify patients at high risk of azathioprine toxicity, who might more appropriately be treated with one of the new immunosuppressants such as tacrolimus or mycophenolate mofetil.

\section{Acknowledgements}

We thank Jutta Engelmayer and Iris Brandel for their skilful technical assistance.

\section{References}

1. Elion G. Biochemistry and pharmacology of purine analogues. Fed Proc 1967; 26:898-903.

2. Kelley WN, Rosenbloom FM, Seegmiller JE. Effects of azathioprine on purine synthesis in clinical disorders of purine metabolism. J Clin Invest 1967; 46:1518-29.

3. Tidd DM, Paterson ARP. A biochemical mechanism for the delayed cytotoxic reaction of 6-mercaptopurine. Cancer Res 1974; 34:738-46.

4. Elion GB. The purine path to chemotherapy. Science 1989; 244:41-53.

5. Lennard L, Lilleyman JS, Van Loon J, Weinshilboum RM. Genetic variation in response to 6-mercaptopurine for childhood acute lymphoblastic leukaemia. Lancet 1990; 336:225-9.

6. Evans WE, Horner MH, Chu YQ, Kalwinsky D, Roberts WM. Altered mercaptopurine metabolism, toxic effects and dosage requirements in a thiopurine methyltransferase-deficient child with acute lymphatic leukemia. J Pediatr 1991; 119:985-9.

7. Lennard L, Rees CA, Lilleyman JS, Maddocks JL. Childhood leukemia: a relationship between intracellular 6-mercaptopurine metabolites and neutropenia. $\mathrm{Br} \mathrm{J}$ Clin Pharmacol 1983; 16:359-63.

8. Lennard L, Brown CB, Fox M, Maddocks JL. Azathioprine metabolism in kidney transplant recipients. $\mathrm{Br} \mathrm{J}$ Clin Pharmacol 1984; 18:693-700.

9. Bergan S, Rugstad HE, Bentdal O, Stokke O. Monitoring of azathioprine treatment by determination of 6-thioguanine nucleotide concentrations in erythrocytes. Transplantation 1994; 58:803-8.

10. Schütz E, Gummert J, Mohr FW, Armstrong VW, Oellerich M. Should 6-thioguanine nucleotides be monitored in heart transplant recipients given azathioprine? Ther Drug Monit. In press.

11. Weinshilboum RM, Sladek SL. Mercaptopurine pharmacogenetics: monogenetic inheritance of erythrocyte thiopurine methyltransferase activity. Am J Hum Genet 1980; 32:65162.

12. Tinel M, Berson A, Pessayre D, Letteron P, Cattoni MP, Horsmans Y, Larrey D. Pharmacogenetics of human erythrocyte thiopurine methyltransferase activity in a French population. Br J Clin Pharmacol 1991; 32:729-34.

13. McLeod HL, Lin J-S, Pui C-H, Scott EP, Evans WE. Thiopurine methyltransferase activity in American white and black subjects. Clin Pharmacol Ther 1994; 55:15-20.

14. Vuchetich JP, Weinsbhilboum RM, Price RA. Segregation analysis of human red blood cell thiopurine methyltransferase activity. Genetic Epidemiology 1995; 12:1-11.

15. Szumlanski CL, Honchel R, Scott MC, Weinshilboum RM. Human liver thiopurine methyltransferase pharmacogenetics: biochemical properties, liver-erythrocyte correlation and presence of isozymes. Pharmacogenetics 1992; 2:148-59.

16. Van Loon J, Weinshilboum RM. Thiopurine methyltransferase biochemical genetics: human lymphocyte activity. Biochem Genet 1982; 20:637-58.

17. Van Loon J, Weinshilboum RM. Thiopurine methyltransferase isozymes in renal tissue. Drug Metab Dispos 1990; 18:632-8.

18. Krynetski EY, Schuetz JD, Galpin AJ, Pui C-H, Relling MV, Evans WE. A single point mutation leading to loss of catalytic activity in human thiopurine S-methyltransferase. Proc Natl Acad Sci USA 1995; 92:949-53.

19. Otterness DM, Szumlanski CL, Lennard L, Weinshilboum RA. Human thiopurine methyltransferase pharmacogenetics: molecular basis for common genetic polymorphism [abstract]. ISSX Proc 1995; 8:107.

20. Ohlman S, Lafolie P, Lindholm A, Lilliemark J, Tyden G, Peterson C. Large interindividual variability in bioavailability of azathioprine in renal transplant recipients. Clin Transplantation 1993; 7:65-70.

21. Bergan S, Rugstad HE, Bentdal O, Endresea L, Stokke O. Kinetics of mercaptopurine and thioguanine nucleotides in renal transplant recipients during azathioprine treatment. Ther Drug Monit 1994; 16:13-20.

22. McLeod HL, Relling MV, Liu Q, Pui C-H, Evans WE. Polymorphic thiopurine methyltransferase in erythrocytes is indicative of activity in leukemic blasts from children with acute lymphoblastic leukemia. Blood 1995; 85:1897-902.

23. Lennard L, Van Loon JA, Lilleyman JS, Weinshilboum RM. Thiopurine pharmacogenetics in leukemia: correlation of erythrocyte thiopurine methyltransferase activity and 6-thioguanine nucleotide concentrations. Clin Pharmacol Ther 1987; 41:18-25. 
24. Weinshilboum RM, Raymond FA, Pazmino PA. Human erythrocyte thiopurine methyltransferase: radiochemical microassay and biochemical properties. Clin Chim Acta 1978; 85:323-33.

25. Lennard L. Assay of 6-thioinosinic acid and 6-thioguanine nucleotides, active metabolites of 6-mercaptopurine, in human red blood cells. J Chromatogr 1987; 423:169-78.

26. Burton N, Barnett M, Aherne G, Evans J, Douglas I, Lister A. The effect of food on the oral administration of 6-mercaptopurine. Cancer Chemother Pharmacol 1986; 18:90-1.
27. Schütz E, Gummert J, Mohr FW, Oellerich M. Azathioprineinduced myelosuppression in thiopurine methyltransferase deficient heart transplant recipient. Lancet 1993; 341:436.

Received September 15/December 15, 1995

Corresponding author: Dr. med. Ekkehard Schütz, Zentrum Innere Medizin, Abt. Klinische Chemie, Georg-AugustUniversität, Robert-Koch-Straße 40, D-37075 Göttingen, Germany 
